\title{
PENGEMBANGAN APLIKASI GAME EDUKASI MENGAJI DENGAN METODE BELAJAR ALBARQI DASAR PADA YAYASAN MARHAMATUR RIDHO BERBASIS ANDROID
}

\author{
Nurul Rudotul Saddiah Siregar ${ }^{1}$ \\ Fakultas Komputer, Universitas Mohammad \\ Husni Thamrin \\ Email: uyunk.siregar@gmail.com
}

\author{
Tata Sutabri ${ }^{2}$ \\ Fakultas Komputer, Universitas Mohammad \\ Husni Thamrin \\ Email: tata.sutabri@gmail.com
}

\begin{abstract}
Perkembangan teknologi saat ini menjadikan sebuah produk teknologi menjadi barang penting untuk menunjang produktivitas kehidupan sehari-hari. Smartphone adalah salah satu andalan yang sudah menjadi kebutuhan setiap orang di era teknologi sekarang ini dan juga sudah menjadi identitas sekunder bagi sekian banyak masyarakat penggunanya di daerah perkotaan. Karna pada era ini setiap orang lebih menginginkan sesuatu yang di dapat secara instant dan cepat oleh karena itu Smartphone menjadi sebuah pilihan yang menyenangkan di berbagai usia dan jenis pekerjaan. Penelitian ini bertujuan untuk merancang suatu aplikasi mobile edukasi berbasis android, mengimplementasikan dan memeberikan pelajaran kepada setiap anak serta mengenalkan metode pembelajaran Albarqi dengan mudah dan menyenangkan kepada pengguna. Bedasarkan dengan implementasi yang telah di uraikan, peneliti menyimpulkan beberapa pengembangan dalam metode pembelajaran huruf hijaiyah dengan metode belajar Albarqi berbasis android agar memepermudah dalam menghafalkan huruf hijaiyah dengan smartphone. Karena penggunaannya sangat mudah membuat aplikasi ini dapat digunakan dimanapun dan kapapun oleh setiap anak.
\end{abstract}

Kata Kunci : Android, Edukasi, Mobile Game, Play Store

\section{Pendahuluan}

Perkembangan teknologi saat ini menjadikan sebuah produk teknologi menjadi barang penting untuk menunjang produktivitas kehidupan sehari-hari. Smartphone adalah salah satu andalan yang sudah menjadi kebutuhan setiap orang di era teknologi sekarang ini dan juga sudah menjadi identitas sekunder bagi sekian banyak masyarakat penggunanya di daerah perkotaan. Karna pada era ini setiap orang lebih menginginkan sesuatu yang di dapat secara instant dan cepat oleh karna itu
Smartphone menjadi sebuah pilihan yang menyenangkan di berbagai usia dan jenis pekerjaan.

Pada era sebelumnya, handphone hanya dapat digunakan tidak lebih sebagai alat untuk menerima panggilan telepon, mengangkat panggilan telepon dan mebalas menerima pesan teks yang singkat. Hal ini disebabkan karena keterbatasan teknologi pada pada zaman dahulu. Namun dunia pada saat ini berkembang dengan sangat pesat dan teknologi pun juga mengikuti kemajuan dari perkembangan dunia itu sendiri. Seiring dengan perkembangan dunia kemajuan teknologi sangat berpengaruh untuk pengembangan kehidupan di setiap daerah atau negara.

Handphone pun sudah berkembang dengan sangat maju dalam penyajian segala macam kebutuhan manusia mulai dari teknologi mendengarkan musik, memotret hingga berinternet secara bertahap hadir dalam perangkat handphone yang sekarang ini lebih dikenal dengan smartphone atau telepon pintar. Salah satu perkembangan teknologi yang sangat pesat yaitu perangkat android, perangakat ini yang paling banyak diminati berbagai macam kalangan khusus nya anak -anak. Anak dapat bermain dan juga belajar dengan perangkat android seperti tema yang saya ambil yaitu mengenal huruf hijaiyah sebagai pembahasannya. Di jaman sekarang ini anakanak lebih senang bermain dari pada mempelajari dan menghafal huruf -huruf hijaiyah. Banyak anak-anak yang malas membaca buku dan cepat merasa bosan.

Mempelajari huruf -huruf hijaiyah dan mengenal 10 malaikat Allah melalui pengajaran dari orang tua dan guru sulit untuk menyesuaikan waktu dan metode pengajaran yang dapat mengikuti penalaran anak -anak. Anak -anak lebih menyukai pelajaran yang lebih menyenangkan dengan belajar menghafal huruf mengenal 10 Malaikat dengan lagu -lagu yang disukai anak dan juga dapat menghafal sambil bermain. 
Kehadiran aplikasi ini juga memudahkan pemakai untuk lebih memahami, mempelajari, dan mendalami tentang keagamaan khususnya mengetahui huruf -huruf hijaiyah dan mengenal 10 Malaikat yang mungkin telah sering di lupakan atau abaikan. Dengan adanya aplikasi tentang game edukasi mengaji dan mengenal 10 Malaikat ini di platform android diharapkan dapat memperkenalkan, memudahkan, dan menarik minat anak-anak dalam pengetahuan tentang berbagai macam huruf -huruf hijaiyah juga mengenal 10 Malaikat Allah. Dengan metode mengaji yang menyenangkan dan cepat maka penulis menggunakan metode mengaji Albarqi

\section{Metode penelitian.}

Peneliti membutuhkan informasi dan data-data yang berhubungan dengan kajian penulis, yaitu bersumber dari: Studi Pustaka (Library Research) Yaitu pengumpulan data-data dengan cara mempelajari berbagai bentuk bahan-bahan tertulis seperti buku-buku penunjang kajian, catatan-catatan maupun referensi lain yang bersifat tertulis.Studi Lapangan (Field Research) yaitu penelitian dengan cara membandingkan aplikasi yang serupa yaitu aplikasi game edukasi mengenal huruf - huruf hijaiyah yang satu dengan yang lainnya, aplikasi serupa ini didapat dari google play store.

\section{Hasil dan pembahasan}

Analisis sistem adalah penjabaran dari suatu sistem informasi yang utuh ke dalam berbagai bagian komponennya dengan maksud agar bisa mengidentifikasi dan mengevaluasi berbagai macam masalah atau hambatan yang timbul pada sistem sehingga nantinya bisa dilakukan penanggulangan, perbaikan dan juga pengembangan, tujuan untuk mempelajari bagaimana komponen pembentuk sistem tersebut saling bekerja dan berinteraksi untuk mencapai tujuan sistem.

Bedasarkan sistem dari analisis pembelajaran mengaji siswa di Yayasan Marhamatur Ridho. Penulis memperhatikan sistem belajar siswa yang di lakukan sudah menggunakan metode yang baik dan mudah di pahami oleh anak anak akan tetapi masih kurang nya waktu pembelajaran yang lebih praktis sehingga penulis menawarkan solusi dengan membuat aplikasi berbasis Android agar lebih menarik minat belajar siswa saat berada di rumah . Dengan metode mengaji yang sudah ada penulis menerapkannya kedalam sebuah aplikasi Game Edukasi mengaji agar lebih mudah dan menarik di pelajari oleh siswa maupun anak - anak.
Dari hasil analisis diatas penulis mencoba mengusulkan rancangan berupa sistem aplikasi berbasis Andoid dengan harapan sistem yang penulis usulkan dapat membantu minat belajar siswa Yayasan Marhamatur Ridho maupun anak - anak lainnya juga mempermudah proses menghafalkan huruf huruf hijaiyah.

Perancangan sistem merupakan tahapan dari pengembangan sistem yang didefinisikan dari kebutuhan fungsional dan persiapan perancangan implementasi yang menggambarkan bagaimana suatu sistem dibentuk, yang dapat berupa penggambaran, perancangan, dan pembuatan sketsa atau pengaturan dari beberapa elemen yang terpisah kedalam satu kesatuan yang utuh dan berfungsi,juga menyangkut konfigurasi dari perangkat keras dan perangkat lunak suatu sistem. Adapun tampilan dari disain user interface yang akan diimplementasikan, adalah sebagai berikut :

\section{a) Menu Utama}

Pada gambar 1terlihat tampilan output dari menu utama game mengaji albarqi. Terlihat pada menu aplikasi tersebut pengguna dapat memilih menu belajar untuk pembelajaran mengaji albarqi atau memilih menu tebak huruf sebagai menu untuk memulai permainan tebak huruf dan dapat melihat menu 10 malaikat sebagai video pengenalan 10 malaikat Allah.

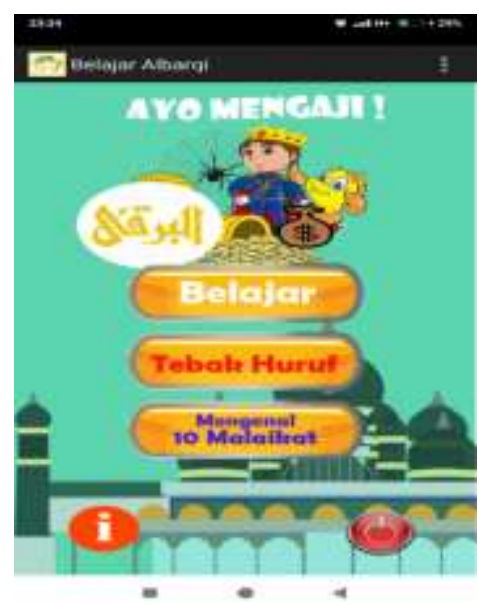

Gambar 1 Tampil Menu Utama

\section{b) Menu Belajar}

Pada gambar 2. terlihat tampilan output dari menu belajar game mengaji albarqi. Terlihat pada menu aplikasi tersebut pengguna dapat 
memilih menu Mari belajar sebagai metode pembelajaran atau memilih menu video albarqi untuk melihat video mengaji albarqi dasar.

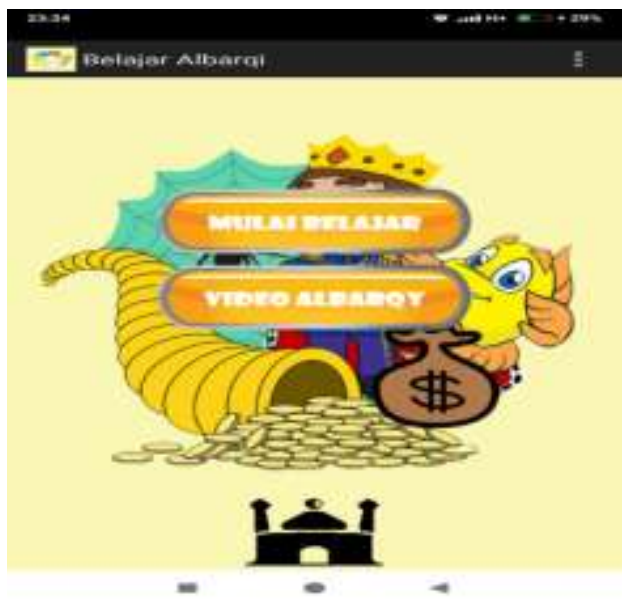

Gambar 2 Tampil Menu Belajar

Gambar 2 Tampil Menu Belajar

\section{c) Menu Albarqi1}

Pada gambar 3 terlihat tampilan output dari menu albarqi1 game mengaji albarqi. Terlihat pada menu aplikasi tersebut pengguna dapat memilih atau menekan tombol huruf - huruf albarqi yang terdapat pada aplikasi untuk mendengarkan macam - macam huruf albarqi dasar dan memilih tombol next untuk melanjutkan pembelajaran.

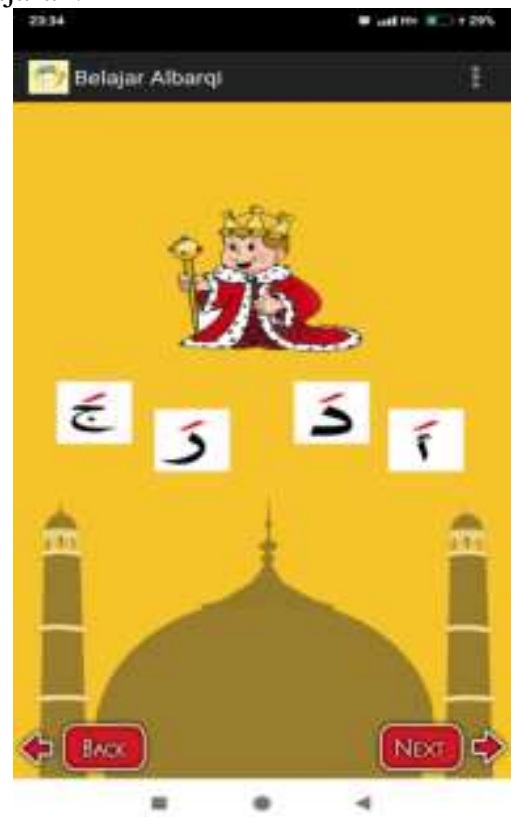

\section{d) Menu Albaqi2}

Pada gambar 4. terlihat tampilan output dari menu albarqi2 game mengaji albarqi. Terlihat pada menu aplikasi tersebut pengguna dapat memilih atau menekan tombol huruf - huruf albarqi yang terdapat pada aplikasi untuk mendengarkan macam - macam huruf albarqi dasar dan memilih tombol next untuk melanjutkan pembelajaran.

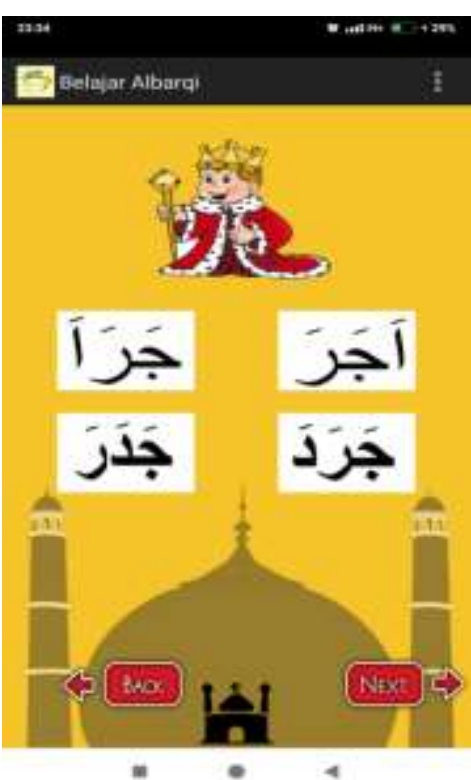

Gambar 4 Tampil Menu Albarqi2

e) Menu Albarqi3

Pada gambar 5 terlihat tampilan output dari menu albarqi3 game mengaji albarqi. Terlihat pada menu aplikasi tersebut pengguna dapat memilih atau menekan tombol huruf - huruf albarqi yang terdapat pada aplikasi untuk mendengarkan macam - macam huruf albarqi dasar dan memilih tombol next untuk melanjutkan pembelajaran. 


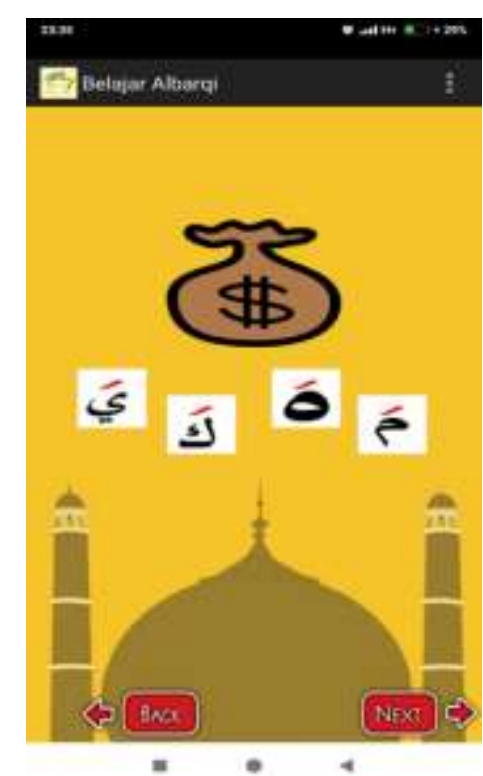

Gambar 5 Tampil Menu Albarqi3

f) Menu Video Albarqi

Pada gambar 7 terlihat tampilan output dari menu video albarqi game mengaji albarqi. Terlihat pada menu aplikasi tersebut pengguna dapat memutar video pembelajaran albarqi untuk anak - anak dan memilih tombol next untuk melanjutkan pembelajaran.

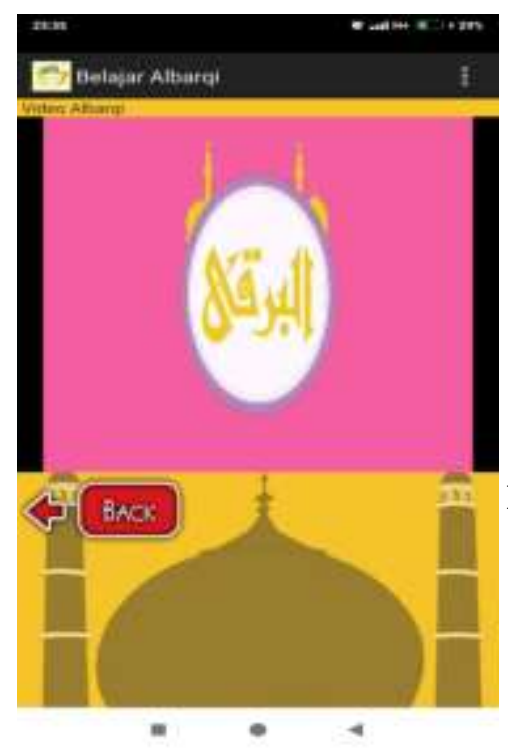

Gambar 6 Tampil Menu Video Albarqi

g) Menu Tebak Huruf

Pada gambar 8 terlihat tampilan output dari menu tebak huruf game mengaji albarqi. Terlihat pada menu aplikasi tersebut pengguna dapat memilih atau menekan tombol huruf - huruf albarqi yang terdapat pada aplikasidengan mengikuti intruksi dari suara hrurf albarqi yang dikeluarkan apabila jawaban benar maka akan terdengan suara yang membenarkan dan apabila salah akan terdengar suara salah.

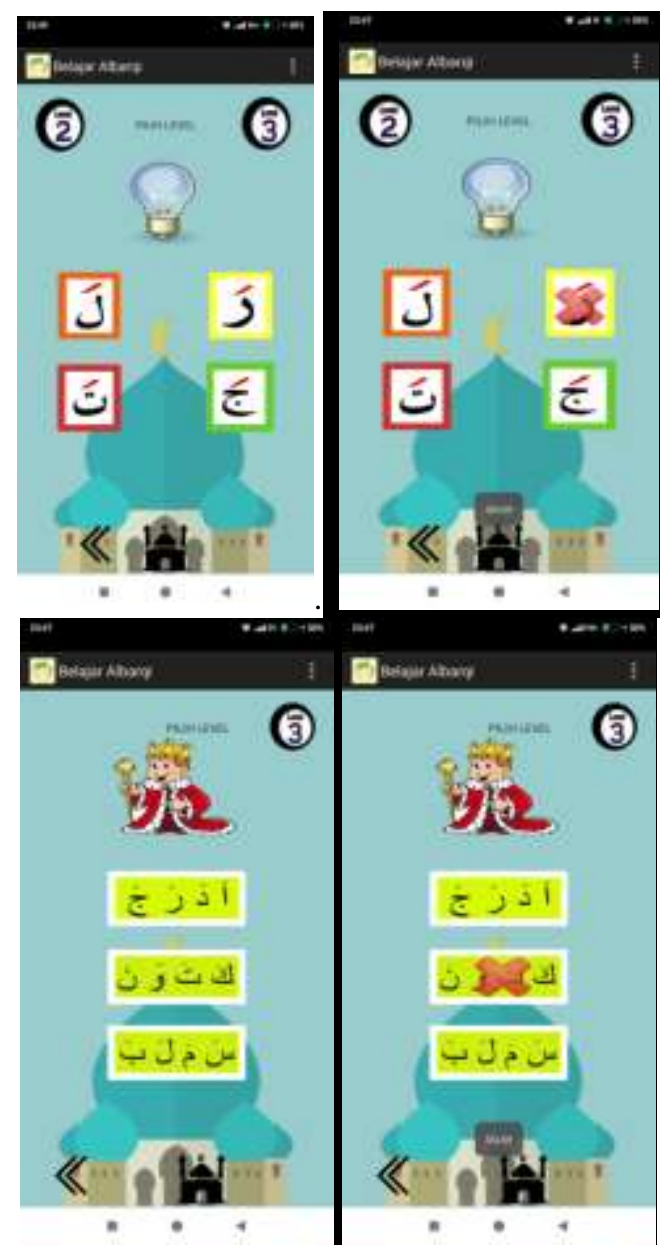

Gambar 7 Tampil Menu Tebak huruf

h) h) Menu About Us

Pada gambar 9 terlihat tampilan output dari menu About us game mengaji albarqi. Terlihat pada menu aplikasi tersebut pengguna dapat melihat pemberitahuan tentang perancang aplikasi Game Mengaji Albarqi. 

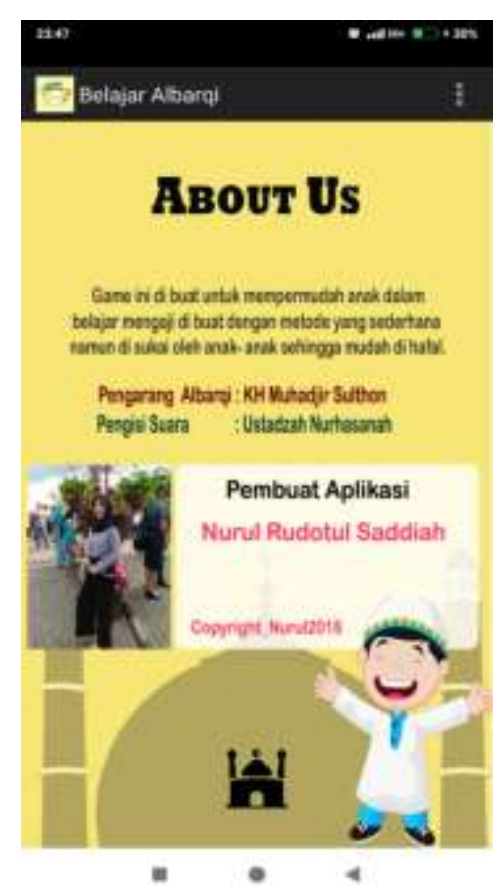

Gambar 8 Tampil Menu About Us

c) Menu 10 Mengenal Malaikat Pada gambar 10 terlihat tampilan output dari menu video albarqi game mengaji albarqi. Terlihat pada menu aplikasi tersebut pengguna dapat memutar video pembelajaran albarqi untuk anak - anak dan memilih tombol next untuk melanjutkan pembelajaran.

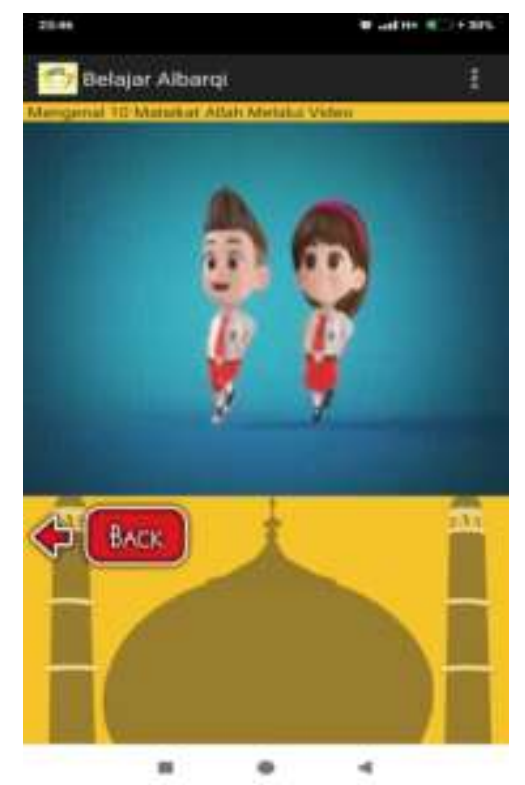

Gambar 9 Tampil Menu 10 Mengenal Malaikat

Spesifikasi Sistem Komputer
Spesifikasi Hardware yang digunakan oleh penulis adalah sebagai berikut:

1. Laptop ASUS A455L Series.

2. Processor Intel(R) CORE i5.

3. RAM 4 GB.

4. System type 32 bit Operating System.

Dan spesifikasi software yang digunakan adalah:

1. Windows 10.

2. Eclipse.

3. Java.

4. XML.

5. Microsoft Visio 2010

\section{KESIMPULAN}

Berdasarkan dari implementasi yang sudah diuraikan sebelumnya, maka dari itu penulis menyimpulkan sebagai berikut:

1. Setiap anak dapat belajar mengenal huruf hijaiyah dengan lebih mudah dan baik lagi menggunakan game mengaji Albarqi.

2. Anak - anak dapat belajar menghafal huruf hijaiyah kapan pun dan dimana pun dengan menggunakan smartphone.

3. Belajar sambil bermain sangat di butuh kan setiap anak karna pembelajaran yang tidak membosankan dan membuat anak - anak tidak menjadi jenuh.

4. Sebagai daya tarik anak - anak untuk lebih giat dalam mempelajari huruf - huruf hijaiyah, agar dapat membaca alquran sebagai tahapan dasar pembelajaran huruf alquran.

5. Setiap anak tidak kesulitan lagi dalam mutola'ah huruf hijaiyah yang sudah di pelajari di tempat mengaji setiap anak.

6. Mempercepat anak dalam mengenal dan menghafal huruf - huruf hijaiyah.

\section{REFERENSI}

-. (2016, 2 2). definisipengertian.net. Retrieved 3 7, 18, from Pengertian Analilis Sistem dan Fungsinya: http://definisipengertian.net/pengertian -analisis-sistem-dan-fungsinya/\#

. (2014, 4 2). pasukansedekah.wordpress.com. Retrieved 3 2, 2018, from Pengertian Video:

https://pasukansedekah.wordpress.com/ 2014/04/16/pengertian-vidio-padamultimedia/

de-tekno.com. (2015, 3 4). Retrieved 2 5, 2018, from fitur Android: https://de- 
tekno.com/2015/11/versi-android-danfitur-fiturnya/

woocara.blogspot.com. (2015, 2 4). Retrieved 2 5, 2018, from sjarah Android: http://woocara.blogspot.com/2015/02/s ejarah-android-dan-nama-nama-versiandroid.html

Andriyanto. (2014, 10 4).

andriyanto0611.blogspot.com. Retrieved 2 3, 2018, from Makalah Albarqi: http://andriyanto0611.blogspot.com/20 14/04/normal-0-false-false-false-en-us$\mathrm{x}$-none.html

Burhan, L. (2014, 12 3).

metodecepatbelajaralquran.blogspot.c om. Retrieved 2018 4, 02, from Sejarah Albarqi:

http://metodecepatbelajaralquran.blogs pot.com/2014/12/penemu-metode-albarqymetode-cepat.html

Hamim, T. (2014). Astah-Analisis serta

Perancangan Sistem Informasi Melalui Pendekatan UML. Yogyakarta: Penerbit Andi.
Mandala. (2014, 12 1). www. mandalamaya.com. Retrieved 2 3, 2018, from Pengertian Game: http://www.mandalamaya.com/pengerti an-game-menurut-para-ahli/

Rahmadani, C. (2015). Dasar Algoritma dan Struktur Data dengan Algoritma. Yogyakarta: Penerbit ANDI.

Rosa, A., \& M. Shalahudin. (2016). Rekayasa Perangkat Lunak. Bandung: Informatika.

Sutabri, T. (2016). Sistem Informasi Manajemen (Edisi Revisi). Yogyakarta: Penerbit ANDI.

Verdi, Y. (2012). Rekayasa Perangkat Lunak Berorientasi Objek: Pemodelan Arsitektur dan Perancangan ( Modeling, Architecture and Design). Jakarta: Mitra Wacana Media.

Yudhanto, Y., \& Wijayanto, A. (2017). Mudah Membuat dan Berbisnis Aplikasi Android dengan Android Studio. Jakarta: Penerbit PT Elex Media Komputindo. 